\title{
Image effects and long distance dependencies
}

\author{
Letícia M.S. Corrêa ${ }^{1}$, Marina R.A. Augusto ${ }^{2}$ \\ ${ }^{1}$ Department of Letters, Pontifical Catholic University of Rio de Janeiro, Brazil \\ ${ }^{2}$ Department of Language Studies, Rio de Janeiro State University, Brazil \\ https://doi.org/10.36505/ExLing-2019/10/0013/000375
}

\begin{abstract}
This study aimed to distinguish the syntactic effect of syntactic movement/featural intervention from the post-syntactic effect of image complexity in children's comprehension of object relative clauses and WH-questions in a picture-identification task. Data from Brazilian Portuguese-speaking seven-year-olds are analysed. The results indicate that image complexity amplifies the number of errors that might be ascribed to an intervention effect. Similar results on WH-questions suggest that the effect of syntactic movement at the interfaces suffices to account for the subject-object asymmetry. Implications for the identification of language impairment in the syntactic domain are considered.
\end{abstract}

Key words: relatrve clauses, sentence comprehension, featural intervention

\section{Introduction}

The subject-object asymmetry in children's comprehension of relative clauses (RCs) with object RCs (ORCs) being more demanding than subject RCs (SRCs) has been widely attested (Adani 2011, Corrêa 1995, de Villiers, Hakuta, Cohen 1979, Diessel, Tomasello 2000) (1-2).

(1) Show me the horse that kicked the cow. (SRC)

(2) Show me the horse that the cow kicked. (ORC)

A number of explanations for this asymmetry have been provided, focusing on the possible consequences of syntactic movement on the processing load (Corrêa 1995, Gibson, Desmet, Grodner, Watson, Ko 2005, Wanner, Maratsos 1978). In a different vein, the featural intervention hypothesis proposes that the subject of ORCs functions as an intervener thereby blocking syntactic movement, if the Relativized Minimality principle (Rizzi 1990) is overextended or generalized (Friedmann, Belletti, Rizzi 2009, Friedmann, Novogrodsky 2006, Grillo 2009). The relevant feature distinguishing the subject and the object of the $\mathrm{RC}$, thereby promoting syntactic movement (WH+move) would fail to be recognized, retrieved or maintained in working memory.

The assessment of children's syntactic abilities has been typically conducted in the sentence-picture matching paradigm, which contributes to the identification of language impairment in the syntactic domain. Post-syntactic processes pertaining to the mapping of the semantic interpretation of the

ExLing 2019: Proceedings of $10^{\text {th }}$ International Conference of Experimental Linguistics, 25-27 September 2019, Lisbon, Portugal 
sentence onto pictures may, nevertheless, add to the overall processing difficulty. The aim of this study is to tease apart the effect of syntactic movement/featural intervention from post-syntactic effects stemming from image complexity on the comprehension of RCs by children.

\section{Syntactic demands and image complexity}

In the present study, a battery of tests for the assessment of language comprehension abilities of Brazilian Portuguese (BP) schoolchildren (MABILIN, Correa, 2000) was used, in which image complexity was manipulated. Data obtained in the comprehension of restrictive right-branching RCs (3-4) and bare WH-questions (5-6) are analysed here. RCs would be vulnerable to featural intervention, unlike bare WH-questions. For the latter, subject-object asymmetry would more likely be due to the consequences of syntactic movement to sentence processing.

(3) Mostra o urso que pegou o tigre. (SRC) Show the bear that caught the tiger.

(4) Mostra o leão que o tigre pegou. (ORC) Show the lion that the tiger caught.

(5) Quem limpou o elefante? (Bare SWH-Q) Who cleaned the elephant?

(6) Quem o porco chamou? (Bare OWH-Q) Who did the pig call?

For each test-sentence, a background picture is provided with the relevant event introducing the referent of the +WH element as the actor/ patient of the action (the target referent). Children are requested to identify this referent in a set of three options. The complexity of the images is manipulated as follows: Simple images (SI) present a single event (the relevant event) and a third character standing by the scene. Complex images (CI) present two similar events: the target one and another one with reversed roles. (See Figures 1-3 for SI and 2-4 for CI ORCs and OWH-Qs).

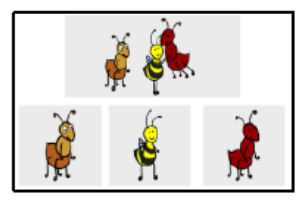

Fig.1 SI ORC

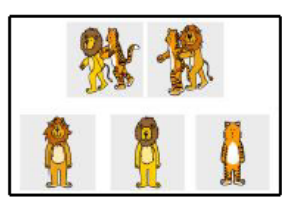

Fig.2.CI ORC

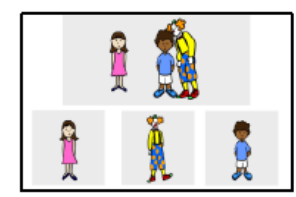

Fig.3 SI OWH-Q Fig.4 CI OWH-Q

For both sentence types, the independent variables were image complexity (simple and complex) and moved element (subject and object). The dependent variables were the number of target responses; the number of referential errors (the second token of the same type as the target one in RCs/the additional 
character in WH-questions) and the number of subject interference/intervention errors in object structures.

It was expected that the subject-object asymmetry was more evident in RCs. Complex images were predicted to be more demanding. This demand was expected to affect ORCs in particular and be manifested in the subject interference/intervention errors.

The participants were sixty-eight 7-year-olds (37 girls, mean age 7.5) Brazilian Portuguese (BP) speakers, enrolled in the Rio de Janeiro public school system (predominantly low-middle social-economic status), with no report of language or other cognitive impairment. The material consisted of eight sentences in each condition defined by moved element presented either in a simple or complex image condition. There were, therefore, four trials for each of the test conditions. A laptop computer and the MABILIN program were used. Children were invited to play a computer game with the experimenter in an isolated room of the school. The sentences were orally presented by the experimenter. The test took about 25 minutes.

\section{Results}

For both RCs and WH-questions, correct responses (1) were submitted to a $2 \times 2$ ANOVA with two within-subject factors. Referential (2) and subject interference/intervention errors (3) were analysed by means of the Friedman test for repeated measures.

For RCs: (1): main effects of image $(\mathrm{F}(1,67)=26.2 \mathrm{p}<.001)$ (Means: 3.76 (SI); $3.37(\mathrm{CI})$ ) and moved element $(\mathrm{F}(1,67)=24.5 \mathrm{p}<.001)$ (Means: $3.75(\mathrm{~S}) ; 3.38(\mathrm{O})$ ); 2-way interaction $(\mathrm{F}(1,67)=13.1 \mathrm{p}<.001)$ (Means: 3.81(SI S); 3.71(SI O); 3.69 (CI S); 3.04 (CI O)). (2): No significant effects. (3): image effect: $X^{2} \mathrm{r}=12.3676$ (1, N = 68), $\mathrm{p}<.0001$ (Sums: 87.5 (SI); 116.5 (CI)).

For WH-questions: (1) main effects of image $(\mathrm{F}(1,67)=10.5 \mathrm{p}<.01)$ (Means: $3.9(\mathrm{SI}) ; 3,7(\mathrm{CI})$ ) and moved element $(\mathrm{F}(1,67)=12.4 \mathrm{p}<.001)$ (Means: $3.89(\mathrm{~S}) ; 3,71$ (O). (2): No significant effects. (3): image effect: $X^{2} \mathrm{r}=5.3088(1, \mathrm{~N}=68), \mathrm{p}=$ .02 (Sums : 92.5 (SI); $111.5(\mathrm{CI})$ ).

\section{Discussion and final remarks}

The results show that for RCs, a clear subject-object asymmetry can be specially observed in the complex image condition and the demands of the object structures are particularly manifested in the subject interference/intervention errors. That is, children are more likely to point to the referent of the intervening subject. For WH-questions, there is no interaction between image and moved element in the number of correct responses, suggesting that the impact of the complex image does not affect the successful processing of these sentences, even though subject interference/intervention errors are also more likely to occur in the complex image condition. The predictions are thus confirmed. Image complexity amplifies the number of errors that might be 
ascribed to an intervention effect in ORCs or to subject interference in both types of sentences, though affecting RCs in particular. The fact that these errors are post-syntactic and were also amplified in object WH-questions causes into question the intervention hypothesis. It appears that the effect of syntactic movement on sentence processing at the interfaces suffices to account for the subject-object asymmetry, regardless of RM. These results should be taken into account when the assessment of language abilities is considered for the identification of language impairment in children. Even though the processing of long-distance dependencies in the most demanding conditions can distinguish linguistic abilities, it is the difficulty imposed by object structures with simple images that would more likely provide an alarm sign for language impairment.

\section{Acknowledgements}

FAPERJ: E-24/202.959/2017;CAPES-PRINT; Prociência FAPERJ.

\section{References}

Adani, F. 2011. Rethinking the acquisition of relative clauses in Italian: Towards a grammatically based account. Journal of Child Language, 38(1), 141-165.

Corrêa, L.M.S. 1995. The relative difficulty of children's comprehension of relative clauses: A procedural account. In Nelson, K.E., Réger, Z. (Ed.), Children's Language (vol.8) (pp. 225-244). Hillsdale: Lawrence Erlbaum.

de Villiers, J.G., Hakuta, K., Cohen, M. 1979. Children's comprehension of relative clauses. Journal of Psycholinguistic Research, 8(5), 499-518.

Diessel, H., Tomasello, M. 2000. The development of relative clauses in spontaneous child speech. Cognitive Linguistics, 11(1/2), 131-151.

Friedmann, N., Belletti, A., Rizzi, L. 2009). Relativized relatives: Types of intervention in the acquisition of A-bar dependencies. Lingua, 119(1), 67-88.

Gibson, E., Desmet, T., Grodner, D., Watson, D., Ko, K. 2005. Reading relative clauses in English. Cognitive Linguistics, 16(2). 313-353.

Grillo, N. 2009. Generalized Minimality: Feature impoverishment and comprehension deficits in agrammatism. Lingua, 119(10), 1426-1443.

Wanner, E., Maratsos, M. 1978. An ATN approach to comprehension. In Halle, M, Bresnan, J., Miller, G.A. (Ed.), Linguistic Theory and Psychological Reality (pp. 119-161). Cambridge, MA: MIT Press. 